\title{
Autoinflammatory Disease Associated to Lymphedema (AISLE) a New Genetic Disease Responding to Anti-IL-1 Treatment and Lymphatic Complex Therapy
}

\author{
Macciò $\mathrm{A}^{1 *}$, Fiore $\mathbf{P}^{2}$, Cavallero $\mathbf{G}^{3}$ and Caruso $\mathbf{S}^{3}$ \\ ${ }^{1}$ LymphoLab ONLUS, Savona, Italy \\ ${ }^{2}$ Giannina Gaslini Institute, Genoa, Italy \\ ${ }^{3}$ Giannina Gaslini Institute, LymphoLab, Italy
}

\section{Background}

Autoinflammatory diseases are a group of inherited conditions other than autoimmune diseases. They are described as disorders characterized by periodic fever and also by episodes of acute inflammation involving the innate immune system. They are causated by a genetic mutation of innate immunity, without involvement of specific immunity. Each inflammatory syndrome has its own peculiar characteristics but in general we can find common characteristics such as: early onset (in childhood or even during the neonatal period), recurrent episodes of fever, multisystemic inflammation, and a broad spectrum of cutaneous manifestations [1]. To date there are new continuous discoveries of gene alterations related to the development of primary lymphedema.

\section{Autoinflammatory syndrome associated with lymphedema (AISLE)}

A frameshift mutation in the MDFIC gene was identified by homozygosity mapping and targeted sequencing using DNA samples of a consanguineous Turkish family as the cause of this syndrome [2]. Clinical findings of these patients are characterized by recurrent attacks of fever, erythematous/urticarial rash with hyperesthesia, myalgia, serositis, chylous serosal effusions, edema/lymphedema on the face and extremities [3].

Because of similar clinical results, one Italian patient was investigated for the same homozygous mutation of the MDFIC gene observed in the two Turkish patients and was found to carry the same mutation. Here we report the case of the Italian patient studied mainly from the point of view of the lymphological follow up.

\section{Methods}

We will describe the history of 16 year girl patient suffering from birth (surgical cesarean at 33rd week of pregnancy) by widespread lymphostasis and pleural effusion (with respiratory distress). The patient had also lost her hearing at 9 months for the mutation of $35 \mathrm{delG}$ of GJB2 gene (currently the patient has a cochlear implant).

Since birth she suffered by recurrent episodes of fever, severe peripheral edema with pleural and pericardial effusion treated with surgical drainage, antibiotic therapy, diuretics and steroids. During the years she also progressively developed a severe diffuse lymphedema.

\section{Rheumatological treatment}

At the age of 8 years, the patient was admitted to the intensive care units for a severe inflammatory recurrence. Antibiotics were largely ineffective and only steroid treatment was able to control the severe inflammatory condition. In the following months the girl become steroid-dependent. For this reason the treatment with anakinra (interleukin-1 receptor antagonist) was started. This has allowed a good complete control of the inflammatory manifestations acute disease, with a rapid withdrawal of steroid. Anakinra was administered for 4 years and it was suspended in September 2014.

The clinical picture observed in our patient was very similar to those of two recently described Turkish cousins presenting the same association of recurrent episodes of inflammation associated to lymphedema. Homozigousity mapping performed in these two patients allowed the identification of a possible causative gene called MDFIC, also known as HIC (Human I-mfa domain containing protein), a transcription factor modulated by IL-2 and expressed by cells of the immune system [3]. Our patient carried the same homozygous mutation of MDFIC gene observed in the two Turkish patients. After discharge, the patient still had significant diffuse edema that severely affected her and a low quality of life.

Complex decongestive therapy (CDT) associated in our protocol with IPC (Intermittent pneumatic compression)

Lymphoscintigraphic [4] patterns of limbs confirmed a generalized lymphostasis (Figure 1). The young girl was treated therefore from the lymphological point of view with traditional CDT [5-8] that includes two phases: attack phase which aims to reduce the volume of lymphedema and maintenance phase to preserve the result. In the attack phase, a complex decongestive therapy was used, mainly multilayer (multicomponent) inelastic bandage [9] and manual lymphatic drainage (MLD) associated with IPC [5,7,10-12] (intermittent pneumatic compression) with daily and three-weekly frequency up to the maximum achievable volume reduction and stabilization of the clinical picture (Figure 2). In the maintenance phase, elastic compression (socks) of KKL II (RAL) (23-34 mmHg) pantyhose and knee-highs (alternating) associated with MLD and IPC was used with eight one-week sessions for two cycles a year (no compression was necessary for the upper limbs after their decongestion of the acute phase). In all phases skin care and specific exercises have been recommended.

\section{Diet therapy}

The serous effusions detected in the patient have caused suspicion of

*Corresponding author: Macciò A, General Surgeon, Clinical Lymphologist, President of LymphoLab ONLUS, Savona, Piazza Santa Cecilia n.4/2, 17100 Savona, Italy, Tel: +39 0464/420795; E-mail: segreteria@linfologia.it

Received February 19, 2018; Accepted March 02, 2018; Published March 08 , 2018

Citation: Macciò A, Fiore P, Cavallero G, Caruso S (2018) Autoinflammatory Disease Associated to Lymphedema (AISLE) a New Genetic Disease Responding to Anti-IL-1 Treatment and Lymphatic Complex Therapy. J Blood Lymph S1: 001. doi:10.4172/2165-7831.S1-001

Copyright: $\odot 2018$ Macciò A, et al. This is an open-access article distributed under the terms of the Creative Commons Attribution License, which permits unrestricted use, distribution, and reproduction in any medium, provided the original author and source are credited. 
Citation: Macciò A, Fiore P, Cavallero G, Caruso S (2018) Autoinflammatory Disease Associated to Lymphedema (AISLE) a New Genetic Disease Responding to Anti-IL-1 Treatment and Lymphatic Complex Therapy. J Blood Lymph S1: 001. doi:10.4172/2165-7831.S1-001

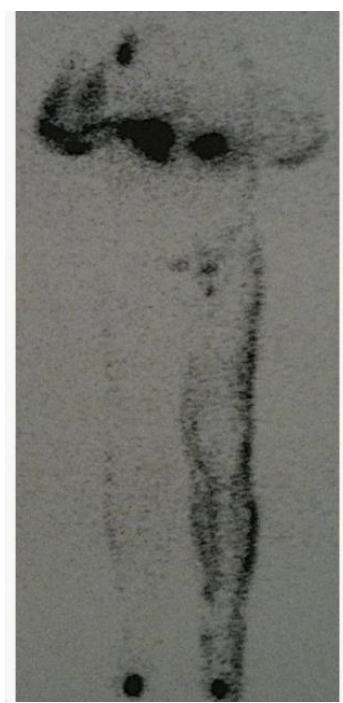

Figure 1: Lymphoscintigraphy (2010): generalized lymphostasis.

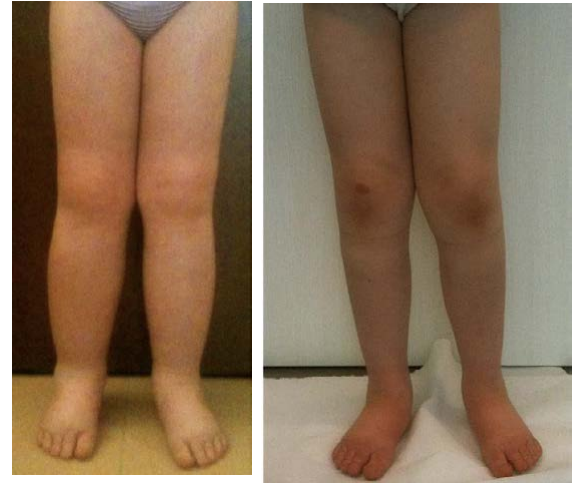

Figure 2: Clinical status before (left) and after (right) intensive phase and strict diet.

an abdominal lymphangiodysplastic component, with involvement of chyliferous vessels. Therefore, the patient was subjected to diet therapy free of long and short-chain triglycerides, the main constituents of the chyle, thus reducing the exogenous chyle load.

The girl has been treated with a high-protein, hypolipidic restricted diet with very low fat content in long chain (minimum fat diet), with integration of medium chain triglycerides (MCT oil) as a source of calories to complete the energy requirements.

The first dietary prescription (the girl was 3 years) has been consisted of a normocaloric diet (1440 kcal) high in protein $(\mathrm{g} 4.5 / \mathrm{kg}$ body weight/day, $18.5 \%$ total kcal); LCT g 12 (7.5\% total kcal), MCT g 25 (15\% total kcal). The diet has been integrated both with vitamin and mineral supplementation to promote the coverage of fat-soluble vitamins and $\mathrm{Ca}++$, and with an integration in essential fatty acids (EFAs) to compensate for the lack of essential omega fatty acids -3 and omega-6. A periodic dietetic counselling has been provided by dietitian to ensure good compliance with dietary fat restriction, and to help the patient to reach nutritional needs to achieve and maintain a good nutritional status and normal growth.

\section{Results}

After ten years of lymphological follow-up the lymphedema is under control (Figure 3). To date, (Anakinra has been suspended for about three years) the reduction of lymphostatis through the traditional therapeutic approach (CDT+ IPC) in association with strict hypolipidic diet has allowed the remission of frequent acute clinical disease. The girl undergoes monthly lymphologic checks and two treatments a year distributed in spring and autumn. She has a completely normal life, she performs daily physical activity (skating), and continues with strict hypolipidic diet. She wears compression stockings of KKL II (RAL) (23-34 mmHg) alternating pantyhose/knee-highs.

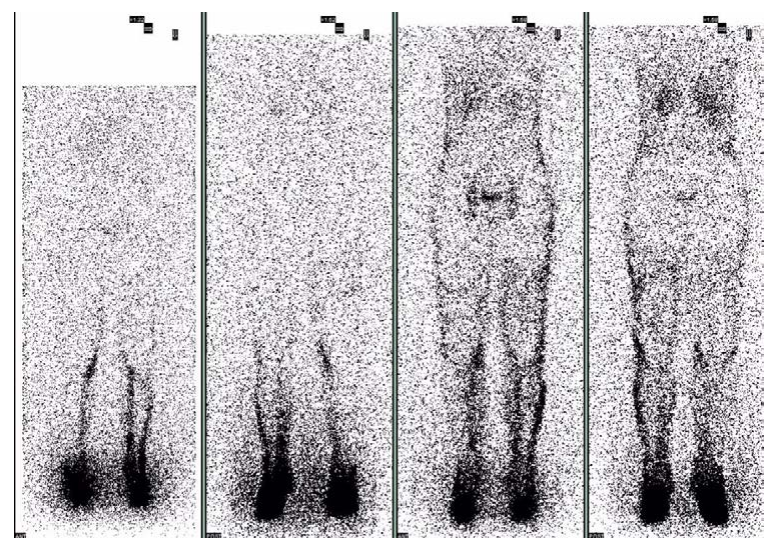

Figure 3: Lymphoscintigraphy after 8 years of treatment: the superficial circle is ectatic and slowed down. There is a poor uptake of inguino-iliac-lomboaortic lymph nodes. No abdominal or pleural effusion of Lympha or Chilo.

\section{Conclusion}

What's the real connection between the mutation of MDFIC and the lymphatic disease? In this case how a autoinflammatory reaction is triggered (AISLE)? The reduction of lymphostatis through the traditional therapeutic approach in association with strict hypolipidic diet has allowed the remission of frequent acute clinical disease or the use of an receptorial antagonist of IL1 can be of help in the control of acute sterile inflammatory lymphangitis?

The importance of multidisciplinary clinical treatment is evident.

From the lymphological point of view the total body lymphologic assessment (especially of the splanchnic district in primary lymphedema) appears fundamental to decide whether it would be useful to reduce the chylose component, as in this case, using a hypolipidic diet with appropriate integration with MCT oil. Every patient in whom a picture of primary lymphedema is suspected must therefore be submitted in addition to an accurate clinical examination by an expert lymphologist, must perform US-scan and doppler evaluation of the limbs, lymphoscintgraphy total body, Lymphangio -MR thorax and abdomen in addition to a genetic control.

If a patient diagnosed with a primary syndromic (genetic or constitutional) picture also has edema must be carefully evaluated also from the lymphological point of view, the presence of untreated peripheral edemas could cause serious complications (first of all lymphangitis) as well as an invasive disability related to the volumes of the arts.

\section{Competing Interests}

The authors declare that they have no competing interests. 
Citation: Macciò A, Fiore P, Cavallero G, Caruso S (2018) Autoinflammatory Disease Associated to Lymphedema (AISLE) a New Genetic Disease Responding to Anti-IL-1 Treatment and Lymphatic Complex Therapy. J Blood Lymph S1: 001. doi:10.4172/2165-7831.S1-001

\section{References}

1. Hernández-Ostiz S (2017) Autoinflammatory Diseases in Pediatric Dermatology-Part 1: Urticaria like Syndromes, Pustular Syndromes, and Mucocutaneous Ulceration Syndromes. Actas Dermosifiliogr 108: 609-619.

2. Gul A, Ustek D, Hatemi G, Ozdogan H (2011) An Insertion Mutation in the MDFIC (MyoD Family Inhibitor Domain Containing) Gene Defines a Novel Autoinflammatory Syndrome Associated with Lymphedema. Conference Paper in Arthritis and Rheumatology 63.

3. Gul A, Bozkurt Y, Demir A, Erman B (2015) Unified modeling of Familial Mediterranean Fever and Cryopyrin Associated Periodic Syndromes. Pediatr Rheumatol 13: 043.

4. Szuba A, Shin WS, Strauss H, Rockson SG (2003) The third circulation: radionuclide lynphoscintigraphy in the evaluation of lymphedema. J Nucl Med 44: 43-57

5. International Society of Lymphology (2013) The diagnosis and treatment of peripheral lymphedema: 2013 consensus document of the International Society of Lymphology. Lymphology 46: 1-11.
6. Pappas CJ, O'Donnel TF (1992) Long-term results of compression treatment for lymphedema. J Vasc Surg 16: 555

7. Földi E, Földi M (1993) Physiothérapie complexe décongestive : soins de la peau, drainage lymphatique manuel, bandages de compression, gymnastique. Paris, Editions Frison-Roche, 1993.

8. Lymphoedema framework. Best practice for the Management of Lymphoedema. International consensus. London: MEP Ltd, 2006.

9. Macciò A (2015) Compression in Dermato-Lymphangio-Adenits Veins \& Lymphatics. Cinderella indications for compression-International Compression Club (ICC) Meeting.

10. Lee BB, Andrade M, Antignani PL, Boccardo F, Bunke N, et al. (2013) Diagnosis and treatment of primary lymphedema consensus document of the international union of phlebology (IUP)-2013. Int Angiol 32: 541-574.

11. The diagnosis and treatment of peripheral lymphoedema: 2009 Consensus Document of the International Society of Lymphology. Lymphology 42: 51-60

12. Stout N, Partsch H, Szolnoky G, Forner-Cordero I, Mosti G, et al. (2012) Chronic edema of the lower extremities: international consensus recommendations for compression therapy clinical research trials. Int Angiol 31: 316-329. 